\title{
História, História da literatura, História da tradução: a tarefa-renúncia
}

\author{
Karina de Castilhos Lucena ${ }^{1}$ \\ Programa de Pós-Graduação em Letras, Universidade Federal do Rio Grande do Sul, Porto Alegre, RS, Brasil
}

Resumo: Este texto propõe entender a noção tarefa-renúncia (Aufgabe), de Walter Benjamin, como um procedimento orientador para a escrita de histórias. Encontramos em textos de Benjamin orientações sobre a tarefa do historiador, do historiador literário, do crítico e do tradutor. A proposta aqui é utilizar as premissas benjaminianas sobre a escrita da história e da história literária para pensar a história da tradução. Para ilustrar o argumento, apresentamos dois exemplos de histórias da tradução que poderiam ser compreendidas a partir do modelo benjaminiano exposto aqui: La Constelación del Sur: traductores y traducciones en la literatura argentina del siglo XX, de Patricia Willson (2004) e Borges y la traducción: la irreverencia de la periferia, de Sergio Waisman (2005).

Palavras-chave: Walter Benjamin; História da tradução; Literatura argentina.

Title: History, History of Literature, History of Translation: task/renunciation

Abstract: The aim of this text is to take Walter Benjamin's concept of task/renunciation (Aufgabe) as a guiding procedure to the writing of histories. In Benjamin's texts we find guidelines about the task of historians, literature historians, critics and translators. What we propose here is to use Benjamin's premises about the writing of History and Literature History to conceive the History of Translation. To elucidate our point, we present two examples of Histories of Translation that could be understood by way of the Benjamin's model exposed in the text: Patricia Willson's La Constelación del Sur: traductores y traducciones en la literatura argentina del siglo XX (2004) and Sergio Waisman's Borges and translation: the Irreverence of the Perifhery (2005).

Keywords: Walter Benjamin; History of Translation; Argentine Literature.

O ensaio A tarefa do tradutor (1921), de Walter Benjamin, é um clássico da teoria da tradução. Para o português, o texto tem pelo menos quatro traduções que, a cada nova edição, passa por revisão dos tradutores, numa mostra da vitalidade do ensaio ${ }^{2}$. Por exemplo, Susana Kampff Lages, tradutora que a cada nova edição do texto, revisa-o e atualiza-o: em 2001 e 2008 traduziu o título por A tarefa-renúncia do tradutor, alterando

\footnotetext{
${ }^{1}$ Professora do Instituto de Letras e do Programa de Pós-Graduação em Letras da Universidade Federal do Rio Grande do Sul - UFRGS. Orcid: http://orcid.org/0000-0001-5254-514X E-mail: kclucena@gmail.com

${ }^{2}$ Uma edição reunindo quatro traduções do ensaio de Benjamin para o português foi organizada por Lucia Castello Branco: A tarefa do tradutor, de Walter Benjamin: quatro traduções para o português. Belo Horizonte: FALE/UFMG, 2008.
} 
para A tarefa do tradutor em edições de 2010 e $2011^{3}$. Nessa última edição - presente no livro Escritos sobre mito e linguagem, com textos de Benjamin escritos entre 1915 e 1921, organização, apresentação e notas de Jeanne Marie Gagnebin - a editora registra em nota:

No original, "Die Aufgabe des Übersetzers". O verbo aufgeben, do qual provém o substantivo Aufgabe, significa "entregar", no duplo sentido do termo: "dar" (geben) algo a alguém para que cuide disso (por exemplo, entregar uma carta ao correio), mas também dar algo a alguém, abrindo mão da posse do objeto (por exemplo, entregar uma cidade ao inimigo). A segunda acepção é mais forte no uso intransitivo do verbo: ich gebe auf"renuncio", "desisto", "me entrego". Essa ambivalência está presente no substantivo Aufgabe, entendido como "proposta", "tarefa", "problema a ser resolvido", mas no qual ressoam também as ideias de "renúncia" e "desistência". (GAGNEBIN in BENJAMIN, 2013, p. 101)

Proponho entender tarefa-renúncia como um procedimento benjaminiano para além do canônico ensaio sobre o tradutor. Baseio essa premissa na recorrência da noção em outros ensaios de Benjamin: João Barrento, editor e tradutor dos textos de Benjamin reunidos em Linguagem, Tradução, Literatura ${ }^{4}$, inclui nesse livro $A$ tarefa do tradutor e $A$ tarefa do crítico (1931). A argentina Mariana Dimópulos deu o título La tarea del crítico para a sua edição de textos de Benjamin ${ }^{5}$. Jeanne Marie Gagnebian e Marcos Lutz Müller, em sua tradução das teses Sobre o conceito de história $(1940)^{6}$, registram a tarefa do historiador segundo Benjamin. Minha ignorância em língua alemã me impede de rastrear a Aufgabe nos originais de Benjamin. Por outro lado, a consistente tradição brasileira de crítica e tradução de Walter Benjamin me dá segurança para conjecturar que tarefa-renúncia é mais do que um problema tradutório pontual; pode ser uma noção iluminadora para o debate sobre escrita da história, da história literária e da história da tradução.

\footnotetext{
${ }^{3}$ Conheço as seguintes edições da tradução de Suzana Lages para o ensaio de Benjamin: em 2001, HEIDERMANN, Werner (org.). Clássicos da teoria da tradução: alemão-português. Florianópolis: UFSC; em 2008, na edição de Lucia Castello Branco citada na nota anterior; em 2010, na segunda edição, revisada e ampliada, do livro organizado por Werner Heidermann; e em 2011, na edição de Escritos sobre mito e linguagem, a cargo de Jeanne Marie Gagnebin, para a Editora 34.

${ }^{4}$ BENJAMIN, Walter. Linguagem, tradução, literatura (filosofia, teoria e crítica). Edição e tradução de João Barrento. Belo Horizonte: Autêntica, 2018.

${ }^{5}$ BENJAMIN, Walter. La tarea del crítico. Edição de Mariana Dimópulos, tradução de Ariel Magnus. Buenos Aires: Eterna cadencia, 2017.

${ }^{6}$ Utilizo a tradução presente em LÖWY, Michael. Walter Benjamin: aviso de incêndio - Uma leitura das teses "Sobre o conceito de história". Tradução de Wanda Nogueira Caldeira Brant. Tradução das teses Jeanne Marie Gagnebian e Marcos Lutz Müller. São Paulo: Boitempo, 2005.
} 


\section{A tarefa-renúncia do historiador}

Não parece absurdo afirmar que as teses Sobre o conceito de história são para a teoria da história o que $A$ tarefa do tradutor representa para a teoria da tradução: um texto fundacional. Em ambos os campos - a história e os estudos de tradução -, Benjamin é nome incontornável, embora certa heterodoxia de pensamento (a fusão entre messianismo e materialismo, para ficar na ambiguidade mais evidente) não o localize plenamente em nenhuma área. Longe de constituir demérito, essa perspectiva de viés, de quem exerce a liberdade do forâneo, provavelmente seja uma das potências do pensamento benjaminiano, sempre desconfiado dos dogmatismos de sua época.

As teses Sobre o conceito de história são daqueles textos de espantosa complexidade. Nas palavras de Jeanne Marie Gagnebin:

Ora, um dos grandes buracos negros do pensamento de Benjamin é certamente, e apesar de várias interpretações simpáticas, mas redutoras, sua teoria da história, mais especificamente da escritura da história e de sua ligação com uma prática transformadora, ao mesmo tempo redentora e revolucionária. O que é, então, esta narrativa salvadora que evocam as famosas teses "Sobre o Conceito de História" e quem é este "historiador materialista" que saberia dizê-lo, enraizado na experiência coletiva dos vencidos? $(2013$, p. 1$)$

Não conseguiria responder a essas perguntas, e mesmo correndo o risco da leitura redutora, vou isolar quatro das teses, na tentativa de demonstrar a tarefa-renúncia do historiador:

- Tese VI: "Articular o passado historicamente não significa conhecê-lo 'tal como ele propriamente foi'. Significa apoderar-se de uma lembrança tal como ela lampeja num instante de perigo [...]". (2005, p. 65)

- Tese VII: “[...] Nunca há um documento de cultura que não seja, ao mesmo tempo, um documento de barbárie. E, assim como ele não está livre da barbárie, também não o está o processo de sua transmissão, transmissão na qual ele passou de um vencedor a outro. Por isso, o materialista histórico, na medida do possível, se afasta dessa transmissão. Ele considera como sua tarefa escovar a história a contrapelo". $(2005$, p. 70$)$

- Tese IX: “Existe um quadro de Klee intitulado 'Angelus Novus'. Nele está representado um anjo, que parece estar a ponto de afastar-se de algo em que crava o seu olhar. Seus olhos estão arregalados, sua boca está aberta e suas asas estão estiradas. $O$ anjo da história tem de parecer assim. Ele tem seu rosto voltado para o passado. Onde uma cadeia de eventos aparece diante de nós, ele enxerga uma única catástrofe, que sem cessar amontoa escombros sobre escombros e os arremessa a seus pés. Ele bem que 
gostaria de demorar-se, de despertar os mortos e juntar os destroços. Mas do paraíso sopra uma tempestade que se emaranhou em suas asas e é tão forte que o anjo não pode mais fechá-las. Essa tempestade o impele irresistivelmente para o futuro, para o qual dá as costas, enquanto o amontoado de escombros diante dele cresce até o céu. $\underline{0 \text { que nós }}$ chamamos de progresso é essa tempestade".$(2005$, p. 87)

- Tese XVII: "O Historicismo culmina de direito na história universal. Dela se destaca, pelo seu método, a historiografia materialista, de maneira talvez mais clara do que qualquer outra. A primeira não tem armação teórica. Seu procedimento é aditivo: ela mobiliza a massa dos fatos para preencher o tempo homogêneo e vazio. À historiografia materialista subjaz, por sua vez, um princípio construtivo. Ao pensar pertence não só o movimento dos pensamentos, mas também a sua imobilização. Onde o pensamento se detém repentinamente numa constelação saturada de tensões, ele confere à mesma um choque através do qual ele se cristaliza como mônada. 0 materialismo histórico se acerca de um objeto histórico única e exclusivamente quando este se apresenta a ele como uma mônada". (2005, p. 130 - todos os grifos são meus)

Nas quatro teses, parece haver crítica a certo modelo historicista acumulativo, linear, em que o historiador pretensamente neutro acessa o passado tal como ele foi e o organiza progressivamente rumo a um futuro. Benjamin indica que o centro de uma historiografia que resiste a esse modelo estaria nos "instantes de perigo", na dialética cultura/barbárie, na visada a contrapelo, nos escombros mais que na tempestade, na mônada - essa "constelação saturada de tensões". Para além do caráter messiânico e revolucionário dessa concepção (que reafirma a complexidade das teses) quero evidenciar o aporte metodológico ali contido, a orientação para todos que nos dedicamos à escrita de histórias.

Nesse sentido, a ideia de mônada parece ter grande valor. Segundo Löwy, "a rememoração tem por tarefa, segundo Benjamin, a construção de constelações que ligam o presente e o passado. Essas constelações, esses momentos arrancados da continuidade histórica vazia, são mônadas, ou seja, são concentrados da totalidade histórica" (2005, p. 131). A tarefa do historiador seria, então, reconhecer essas mônadas, identificar esses concentrados de tensões que iluminam o todo. O historiador renunciaria, assim, à grande narrativa linear em prol dos pequenos eventos que, metonimicamente, lançam luz na totalidade do processo ${ }^{7}$.

\footnotetext{
${ }^{7}$ Não desconhecemos o debate sobre micro e macro história - a necessidade de considerar a escala na escrita da história - que ocupa os historiadores pelo menos desde os anos 1980. Não o aprofundaremos por fugir ao objetivo deste texto, centrado na perspectiva de Walter Benjamin que, além de alicerçar a teoria da história, também serve de base para a história literária e a história da tradução.
} 


\section{A tarefa-renúncia do historiador literário}

Ao pensar a história literária, Benjamin também faz uso de um raciocínio metonímico. Em texto de 1931, História literária e ciência da literatura, publicado no jornal alemão Die literarische Welt $^{8}$, o autor, após avaliar diferentes histórias da literatura alemã escritas da primeira metade do XIX até o seu tempo, cita Walter Muschg:

Quanto ao presente, pode dizer-se que ele está, nos seus trabalhos essenciais, quase exclusivamente orientado para a monografia. A geração atual perdeu em grande parte a crença no sentido de uma representação global. Em vez disso, confronta-se com figuras e problemas que, naquela época das histórias universais, Ihe pareciam primar pela ausência". (apud BENJAMIN, 2018, p. 138)

Benjamin referenda a leitura de Muschg - de que a tarefa do historiador literário estaria orientada para a monografia, figuras e problemas pontuais em detrimento de uma história global - e acrescenta:

Confronta-se [a geração atual de historiadores literários] com figuras e problemas - pode ser que esteja certo. Na verdade, o que acima de tudo devia fazer seria confrontar-se com as obras. O ciclo global de vida e de influência das obras deve ser tratado com igualdade de direitos, e mesmo preponderância, em face da história da sua gênese, ou seja: o seu destino, a recepção pelos contemporâneos, as traduções, a sua fama. Dessa forma, a obra configura-se no seu interior como um microcosmo, ou melhor, como um micro-eon. Porque não se trata, realmente, de apresentar as obras literárias no contexto geral do seu tempo, mas sim de levar à representação, no tempo em que surgiram, do tempo que as reconhece - e que é o nosso. E assim a literatura se transforma num organon da História. E a tarefa da história literária é transformá-la nisso, e não as obras escritas em materiais da História. (BENJAMIN, 2018, p. 138)

A obra literária como um microcosmo, como um micro-eon que ilumina o todo. Parece haver semelhança entre esse raciocínio e a mônada apresentada anteriormente. Além disso, Benjamin acrescenta que a análise literária não se presta a somente compreender a gênese da obra: deve ocupar-se de seu "ciclo global de vida", que inclui recepção, tradução e prestígio. Esse tipo de análise localiza o historiador literário no presente, reforçando a ideia de constelação, tão cara a Benjamin. Nessa perspectiva, a tarefa da história literária é estabelecer uma relação dinâmica entre literatura e história,

\footnotetext{
${ }^{8}$ Utilizo a versão disponível em BENJAMIN, Walter. Linguagem, tradução, literatura (filosofia, teoria e crítica). Edição e tradução de João Barrento. Belo Horizonte: Autêntica, 2018.
} 
desviando-se de certo paradigma enciclopedista. No mesmo texto, Benjamin afirma: "só uma ciência que renuncia ao seu estatuto de museu consegue colocar o real no lugar da ilusão" (2018, p. 136).

Em sua atuação como crítico e historiador literário, Benjamin parece ter renunciado a um modelo historiográfico totalizante que costumamos associar ao positivismo. Michel Löwy defende que as análises de Benjamin põem em prática o paradigma da mônada defendido por ele:

Os trabalhos de W. Benjamin sobre Baudelaire são um bom exemplo da metodologia proposta nessa tese [a XVII de Sobre o conceito de história, citada anteriormente]: trata-se de descobrir em As flores do mal uma mônada, um conjunto cristalizado de tensões que contêm uma totalidade histórica. Nesses escritos, desarraigados do curso homogêneo da história, encontra-se conservada e reunida toda a obra do poeta, nesta, o século XIX francês, e, nesse último, "todo o curso da história". A obra "maldita" de Baudelaire guarda o tempo como uma semente preciosa. (2005, p. 132133)

Assim, tanto o historiador quanto o historiador literário benjaminianos renunciam a uma norma da acumulação de dados organizados linearmente a favor de um modelo que identifica pontos de tensão que, analisados verticalmente, possibilitam a compreensão para além deles. Embora Benjamin não tenha se dedicado a pensar na tarefa do historiador da tradução, poderíamos aventar que este operaria em chave aproximada à dos historiadores por ele pautados. Partindo dessa premissa, poderíamos conjecturar sobre a tarefa do historiador da tradução, seguindo também algumas pistas deixadas por Benjamin em $A$ tarefa do tradutor.

\section{A tarefa-renúncia do historiador da tradução}

Em A tarefa do tradutor $^{9}$, Benjamin também contrapõe seu raciocínio ao que ele chama de "defunta teoria da tradução" (2013, p. 108), num movimento semelhante ao adotado nas teses Sobre o conceito de história e no ensaio História literária e ciência da literatura; podemos entender os três textos a partir da chave tarefa-renúncia: Benjamin define a tarefa (do historiador, do historiador/crítico literário, do tradutor) em oposição, ou seja, renunciando, a algo que está posto.

No caso do ensaio sobre o tradutor, o "inimigo" é certa teoria tradicional de tradução centrada na noção de fidelidade e na imutabilidade do original. Benjamin defende a

\footnotetext{
${ }^{9}$ Utilizo a tradução de Susana Kampff Lages incluída em BENJAMIN, Walter. Escritos sobre mito $e$ linguagem. Organização, apresentação e notas de Jeanne Marie Gagnebin. Tradução de Susana Kampff Lages e Ernani Chaves. São Paulo: Editora 34, 2013.
} 
historicidade do original e, com isso, sua transformação e renovação: o original se modifica (2013, p. 107). A tradução aparece, então, como responsável pela vida do original:

[...] cada tradução de uma obra representa, a partir de determinado período da história da língua e relativamente a determinado aspecto de seu teor, tal período e tal aspecto em todas as outras línguas. A tradução transplanta, portanto, o original para um domínio - ironicamente - mais definitivo da língua [...]. Não por acaso, a palavra "ironicamente" faz lembrar argumentações dos românticos. Eles possuíram, antes de outros, uma consciência da vida das obras, cujo mais alto testemunho é dado pela tradução. (BENJAMIN, 2013, p. 111)

A relativização da primazia do original e a positivação da tarefa do tradutor presentes no ensaio de Benjamin redefinem a teoria da tradução, um impacto semelhante ao das teses para a teoria da história, o que nos leva a propor que se fundíssemos esses dois textos, chegaríamos à tarefa do historiador da tradução segundo Benjamin.

Vale lembrar que $A$ tarefa do tradutor é o prólogo de Benjamin para sua tradução de Quadros parisienses, seção de As flores do mal, de Baudelaire, autor a quem Benjamin dedicou parte relevante de seu trabalho crítico - sua mônada, na interpretação de Löwy citada anteriormente. Poderíamos entender o exercício benjaminiano com uma imagem: círculos concêntricos. No primeiro círculo está o Benjamin tradutor, que desfaz e refaz a poesia de Baudelaire, conhece-a em seu plano mais elementar, essencial, e depois valoriza o trabalho tradutório no famoso prólogo. No círculo seguinte, está o Benjamin crítico, sua leitura iluminadora da poesia de Baudelaire, que dispara o próximo círculo - o âmbito da história - o quanto essa leitura nos ensina sobre o XIX francês.

Usei a metáfora geométrica porque é possível associá-la, me parece, à mônada benjaminiana, esse concentrado de tensões. Em $A$ tarefa do tradutor, Benjamin também recorre a uma imagem geométrica para definir o cruzamento entre tradução e original:

Sendo assim, o que resta de significativo para o sentido na relação entre tradução e original pode ser apreendido numa comparação: da mesma forma como a tangente toca a circunferência de maneira fugidia e em um ponto apenas, sendo esse contato, e não o ponto, que determina a lei segundo a qual ela continua sua via reta para o infinito, a tradução toca fugazmente, e apenas no ponto infinitamente pequeno do sentido do original, para perseguir, segundo a lei da fidelidade, sua própria via no interior da liberdade do movimento da língua. (2013, p. 117)

O famigerado debate fidelidade ao original $x$ liberdade da tradução resumido numa imagem: o ponto de contato entre a tangente e a circunferência. Não parece absurdo, embora talvez um pouco arbitrário, relacionar essa fricção ao instante de perigo, à história a contrapelo, à mônada das teses Sobre o conceito de história. São campos e objetivos 
diferentes os de Benjamin, mas persiste certo método em escala, uma leitura que rompe a linearidade para mergulhar no momento de tensão.

\section{Dois exemplos}

A Argentina ${ }^{10}$ parece ser um lugar em que o debate sobre escrita da história da tradução está maduro. Provavelmente por que a inteligência privilegiada de Jorge Luis Borges colocou o tema em pauta já nas primeiras décadas do século XX. Sergio Waisman, no excelente Borges y la traducción (2005), declara:

La necesidad de una nueva conceptuación crítica de la traducción surge para este libro de las innovadoras prácticas y teorías de los propios escritores argentinos, en especial Borges. Deriva de la creencia de que entre las "traducciones propiamente dichas" y los llamados "originales" hay, con mucho, más semejanzas que diferencias. Surge el reto borgeano a la noción de "texto definitivo" y de que a menudo los méritos de una traducción, paradójicamente, residen más en sus infidelidades creadoras que en sus fidelidades. Surge del uso que hace Borges de la irreverencia y del desplazamiento y del hecho de que sus ideas se desarrollan en un contexto específico: Argentina, nación geopolíticamente periférica. Y, a su vez, de que ese margen, reclamado y explotado por Borges como posición particularmente productiva, es un elemento clave en sus teorías y usos de la traducción. $(2005$, p. 22)

No livro, Waisman examina a importância dos argumentos de Borges para a tradução a partir de três ângulos: 1) o Borges teórico da tradução que, em ensaios dos anos 19201930, já anunciava problemas que os estudos de tradução consolidariam apenas cinquenta anos depois (o ceticismo quanto à superioridade do original sobre a tradução e seu caráter de "texto definitivo" e fora do tempo; a tradução como atividade criadora e potente para a cultura de chegada; a consciência de que é diferente pensar da margem e pensar do centro); 2) o Borges ficcionista que incorpora a tradução em seu repertório estrutural e temático - a tradução aparece na superfície dos enredos e também em certa forma de escrita que parte de outro texto, que se estrutura como resposta irreverente ao que foi escrito antes; e 3) o Borges tradutor, que adota a "infidelidade criadora", nos termos de Waisman, como premissa, rompendo com a tradicional noção de transparência e fidelidade ao original. Vale destacar que as ideias de Borges sobre a tradução convergem, em alguma medida, com as de Benjamin. Sergio Waisman demonstrou essa convergência (não isenta de diferenças, obviamente): "El primer punto de contacto [entre Borges e Benjamin] es el uso que ambos

\footnotetext{
${ }^{10}$ Parte do raciocínio apresentado aqui já foi desenvolvido em outro texto, em parceria com Sérgio Karam: Escritores gaúchos traduzidos: levantamento e comentário, ainda no prelo, que integrará a História da literatura do Rio Grande do Sul coordenada por Luís Augusto Fischer.
} 
hacen de la traducción para acceder a una discusión estética". (2005, p. 66). Também: "la movilidad del original es un punto de coincidencia entre Borges y Benjamin" (2005, p. 69).

Waisman confere, portanto, lugar destacado à tradução na obra de Borges. Seu raciocínio depende, porém, da excelência da fortuna crítica borgeana. Nela, se destaca a análise de Beatriz Sarlo, que demonstrou o quanto a dialética cosmopolitismo x localismo é definidora da narrativa do escritor argentino. Em Modernidade periférica (1988) Sarlo já anunciava que no jogo de forças do campo literário argentino nos anos 1920-30, no conflito entre "intelectuais de origem tradicional e intelectuais recém-chegados, de origem imigrante" pesava "a questão da língua (quem fala e escreve um castelhano 'aceitável'), das traduções (quem está autorizado e por quais motivos a traduzir)" (2010, p. 55). O poliglota Borges, respaldado pelo capital cultural de uma família oligárquica, destaca-se nesse cenário e depois vai ocupar lugar eminente em contexto internacional.

Em Borges, un escritor en las orillas (1993) Sarlo aprofunda o exame:

Su obra [de Borges] muestra el conflicto y este libro intentará leerla en esa dimensión desgarrada. He querido mantener esta tensión que, según creo, atraviesa a Borges y constituye su particularidad: un juego en el filo de dos orillas. Busco la figura bifronte de un escritor que fue, al mismo tiempo, cosmopolita y nacional. $(2007$, p. 13)

Uma literatura nacional que tem como centro Borges, esse escritor cosmopolita. Não é estranho que esse caráter "bifronte" se estenda para certa compreensão da literatura argentina como um todo. Waisman defende que os projetos de fundação argentinos especialmente em Sarmiento - empregam ativamente a tradução e o bilinguismo (2005, p. 21). Ricardo Piglia (1998) argumenta na mesma linha, afirmando que a tensão manifesta-se desde o On ne tue point les idées, a famosa frase citada na Advertência do autor, em Facundo: civilização e barbárie. Essa citação em francês, atribuída equivocadamente a Fortoul, seria o último gesto de resistência do homem obrigado a exilar-se pela barbárie. Nas palavras de Piglia:

História ao mesmo tempo cômica e patética, a desse homem perseguido que se exila, foge e escreve em outra língua. Traz o corpo marcado pela violência da barbárie, mas também deixa sua marca: inscreve um hieróglifo em que a cultura é cifrada e que parece a contrapartida microscópica desse enigma que ele tenta traduzir, decifrando a vida de Facundo Quiroga. [...] não devemos esquecer que essa divisa é uma citação: uma frase de Diderot que Sarmiento cita mal e atribui a Fortoul, abrindo assim o capítulo de referências equivocadas, falsas citações, erudição apócrifa, que é um signo da cultura argentina pelo menos até Borges. (2010, p. 18-19)

Sarmiento cita mal. A falsa citação - imprevista ou calculada, não importa inauguraria uma tradição argentina que entende a posição periférica como potência. E essa 
potência está na compreensão de que a tradição argentina está fundada pelo contato entre línguas e, por decorrência, pela tradução. Piglia vai dedicar algumas páginas ao problema tradição e tradução. Em uma de suas aulas dos anos 1990 - reunidas no livro Las tres vanguardias (2016) - ele conclui:

\begin{abstract}
Discutir, entonces, la situación actual de la novela en la Argentina supone tener siempre en cuenta esa tensión entre literatura nacional y literatura mundial que forma parte de la tradición del género. ¿Qué quiere decir una novela argentina si el género parece haberse constituido como lo internacional mismo? La forma de la novela aparece ligada, de modo directo, a problemas de la traducción. (2016, p. 68)
\end{abstract}

Aqui novamente identificamos complementariedade entre os raciocínios de Piglia e Waisman, com o adendo importante de que Piglia, ao tratar de romance, enxerga ainda mais a conexão nacional/internacional, dada a presença de tradução na formação do gênero. Ao dedicar-se ao exame da obra de Borges, que nunca escreveu romance, Waisman limita sua análise a gêneros como o conto e o ensaio.

A leitura que Sergio Waisman faz de Borges, amparada na tradição que interpreta o cosmopolitismo periférico como definidor da cultura argentina (por exemplo, Sarlo e Piglia), pode servir como um exemplo de história da tradução benjaminiana. Borges é a mônada de Waisman (em se tratando de Borges, poderíamos dizer que ele é o aleph de Waisman) - um concentrado de tensões que ilumina a totalidade. Ao analisar a obra de Borges e a importância que a tradução desempenha em sua ficção, Waisman elucida o papel da tradução na literatura argentina.

Outro exemplo, ainda argentino: La Constelación del Sur: traductores y traducciones en la literatura argentina del siglo XX, de Patricia Willson (2004). Para além do título que evoca a famosa imagem benjaminiana (constelação), o livro de Willson também pode ser lido como uma história da tradução na Argentina vista a partir de um concentrado de tensões. Willson reafirma a centralidade de Borges, na mesma linha de Waisman, mas expande a análise para a Revista Sur que, sob o comando de Victoria Ocampo, introduziu na Argentina, via tradução, parte importante da literatura ocidental. Sarlo já havia estudado o tema em Modernidade periférica; o argumento de Willson, no entanto, vai além ao identificar estilos definidos de tradução: Victoria Ocampo, a tradutora romântica; Jorge Luis Borges, o tradutor vanguardista; José Bianco, o tradutor clássico. Cada um desses tradutores poderia ser lido como uma mônada/aleph que, postos em diálogo, formam uma constelação benjaminiana.

A síntese apresentada aqui é lacunar: não dá conta da complexidade dos argumentos de Benjamin para os campos da história, da literatura e da tradução. No entanto, espero ter demonstrado que certa metodologia benjaminiana pode ser uma diretriz relevante para a escrita da história da tradução. A tarefa desse historiador seria identificar concentrados que, examinados pontualmente, revelam andamentos mais amplos, renunciando a um 
historicismo linear e enciclopédico. Os trabalhos de Sergio Waisman e Patricia Willson exemplificam o modelo: ao dissecarem a tradução em Borges e na Revista Sur, escreveram histórias da tradução orientadas por um problema.

\section{Referências}

BENJAMIN, Walter. Escritos sobre mito e linguagem. Organização, apresentação e notas de Jeanne Marie Gagnebin. Tradução de Susana Kampff Lages e Ernani Chaves. São Paulo: Editora 34, 2013.

BENJAMIN, Walter. La tarea del crítico. Edição de Mariana Dimópulos. Tradução de Ariel Magnus. Buenos Aires: Eterna cadencia, 2017.

BENJAMIN, Walter. Linguagem, tradução, literatura (filosofia, teoria e crítica). Edição e tradução de João Barrento. Belo Horizonte: Autêntica, 2018.

BERMAN, Antoine. La era de la traducción: "La tarea del traductor" de Walter Benjamin, un comentario. Traducción de Eugenio López Arriazu. Buenos Aires: Dedalus, 2015.

BORGES, Jorge Luis. El Aleph. Buenos Aires: Alianza editorial, 2006.

BUCK-MORSS, Susan. Walter Benjamin: escritor revolucionario. Buenos Aires: La Marca, 2014.

CASTELLO BRANCO, Lucia (org.). A tarefa do tradutor, de Walter Benjamin: quatro traduções para o português. Belo Horizonte: FALE/UFMG, 2008.

DIMÓPULOS, Mariana. Carrusel Benjamin. Buenos Aires: Eterna cadencia, 2017.

GAGNEBIN, Jeanne Marie. História e narração em Walter Benjamin. São Paulo: Perspectiva, 2013.

HEIDERMANN, Werner (org.). Clássicos da teoria da tradução: alemão-português. Florianópolis: UFSC; 2010.

JOZAMI, Eduardo; KAUFMAN, Alejandro; VEDDA, Miguel (orgs.). Walter Benjamin en la ex ESMA: Justicia, Historia y Verdad: Escrituras de la memoria. Buenos Aires: Prometeo Libros, 2013.

LÖWY, Michael. Walter Benjamin: aviso de incêndio - Uma leitura das teses "Sobre o conceito de história". Tradução de Wanda Nogueira Caldeira Brant. Tradução das teses Jeanne Marie Gagnebian e Marcos Lutz Müller. São Paulo: Boitempo, 2005.

PIGLIA, Ricardo. Crítica y ficción. Buenos Aires: Penguin Random House, 2014.

PIGLIA, Ricardo. La forma inicial: conversaciones en Princeton. Buenos Aires: Eterna Cadencia, 2015.

PIGLIA, Ricardo. Las tres vanguardias: Saer, Puig, Walsh. Buenos Aires: Eterna Cadencia, 2016.

PIGLIA, Ricardo. Respiración artificial. Buenos Aires: Penguin Random House, 2013. 
PIGLIA, Ricardo. Sarmiento, escritor. Tradução de Júlio Pimentel Pinto. In: SARMIENTO, Domingo F. Facundo ou civilização e barbárie. Tradução de Sérgio Alcides. São Paulo: Cosac Naify, 2010.

PRESSLER, Gunter Karl. Benjamin, Brasil. São Paulo: Annablume, 2006.

SARLO, Beatriz. Borges, un escritor en las orillas. Buenos Aires: Seix Barral, 2007.

SARLO, Beatriz. Modernidade periférica: Buenos Aires 1920 e 1930. Tradução de Júlio Pimentel Pinto. São Paulo: Cosac Naify, 2010.

SARLO, Beatriz. Siete ensayos sobre Walter Benjamin. Buenos Aires: Siglos XXI editores, 2011.

SELIGMANN-SILVA, Márcio (org.). Leituras de Walter Benjamin. São Paulo: Annablume, 2007. SELIGMANN-SILVA, Márcio. O local da diferença: ensaios sobre memoria, arte, literatura e tradução. São Paulo: Editora 34, 2005.

VALDERRAMA, Miguel. Traiciones de Walter Benjamin. Adrogué: Ediciones La Cebra, 2015.

WAISMAN, Sergio. Borges y la traducción. Traducción de Marcelo Cohen. Buenos Aires: Adriana Hidalgo editora, 2005.

WILLSON, Patricia. La Constelación del Sur: traductores y traducciones en la literatura argentina del siglo XX. Buenos Aires: Siglo XXI editores, 2017.

WILLSON, Patricia. Página impar: Textos sobre la traducción en Argentina: conceptos, historia, figuras. Buenos Aires: EThos Traductora, 2019.

Recebido em: 20/05/2019

Aceito em: 23/08/2019 